\begin{tabular}{l} 
SCIENCE \& TECHNOLOGY \\
Journal homepage: http://www.pertanika.upm.edu.my/ \\
\hline PERTANIKA
\end{tabular}

\title{
Implementation of Artificial Neural Network to Predict the Permeability and Solubility Models of Gypseous Soil
}

\author{
Imad Habeeb Obead ${ }^{1}$, Hassan Ali Omran ${ }^{2}$ and Mohammed Yousif Fattah ${ }^{2 *}$ \\ ${ }^{l}$ Department of Civil Engineering, College of Engineering, University of Babylon, Hillah, Iraq \\ ${ }^{2}$ Department of Civil Engineering, University of Technology, Baghdad, Iraq
}

\begin{abstract}
The objective of the present study is to make a database that describes the leachingpermeability behavior of collapsible gypseous soil. The data will be implemented to develop ANN prediction models for predicting the saturated coefficient of permeability and percentage of solubility by weight. The complex soil behavior and tedious and time consume in soil testing have driven researchers to use Artificial Neural Network (ANN) as tool for prediction. The objectives of the study were to investigate leaching-permeability behavior of collapsible gypseous soils and to develop ANN models for estimating the saturated coefficient of permeability and solubility of the soils. The MATLAB R2015a software was used to predict the saturated coefficient of permeability and the solubility percentage by weight of gypseous soils. The dataset used in this work included (513) records of experimental measurements extracted from leaching-permeability tests conducted on gypseous soil samples taken from Baher Al-Najaf in Iraq. Four input variables were investigated to have the most important influence on the permeability and solubility percentage by weight. According to the achieved statistical analysis, the ANNs model have a reliable capability to find out the predictions with a high-level of accuracy. The gypseous soils exhibited a high rate of dissolution of soluble minerals content, which caused

ARTICLE INFO

Article history:

Received: 12 February 2020

Accepted: 23 July 2020

Published: 22 January 2021

DOI: https://doi.org/10.47836/pjst.29.1.06

$\overline{\text { E-mail addresses: }}$

eng.imadh2005@yahoo.com (Imad Habeeb Obead)

hassan7745@gmail.com (Hassan Ali Omran)

myf_1968@yahoo.com (Mohammed Yousif Fattah) increase in the coefficient of permeability as the soil samples reach the state of long-term full saturation.

Keywords: Artificial neural networks, electric conductivity, gypseous soil, leaching-permeability tests, MATLABR2015a, solubility of gypsum, total dissolved salts
\end{abstract}

* Corresponding author 


\section{INTRODUCTION}

Collapsible soils or metastable soils are unsaturated soils that undergo a considerable volume change upon saturation with or without additional load. Generally, collapsible soils maintain an open "honey-combed" structure that can induce negative pore water pressure and cementing agents that result in considerable shear strength. As a result of wetting, effective stresses are reduced due to the dissipation of the negative pore water pressure.

The prevalent of Gypseous soils of higher gypsum content (more than 25\%) for shallow depth less than $2 \mathrm{~m}$ according to Barazanji (1973) with particularly northwest and southwest parts of Iraq. Also, for lower content of gypsum in the central and southern parts of Iraq, it is the major problem. This was pointed out in the surrounding area of hydraulic structures in specific, and constructions in general.Numerous researchers investigated and discussed the many factors influencing the behavior of gypseous soils and their hydro-mechanical properties.

Ibrahim and Schanz (2017) examined the improvement of gypsiferous soil properties by using silicone oil to minimize the effects of moisture and gypsum loss. The work was conducted on artificial gypsiferous soil (30\% Silber sand and 70\% pure gypsum) treated with silicone oil in different percentages. Silicone oil was selected as an additive because of leakages of oil-related products from an oil refinery north of Iraq built on gypsiferous soil. Thus, this oil product provided a suitable analogue for oil that had infiltrated the foundation soil of the refinery buildings. The results showed that the silicone oil was a suitable material for modifying the basic properties of the gypsiferous soil, such as collapsibility and shear strength.

Fattah and Dawood (2020) tried to investigate the behavior of the gypseous soils and the effect of factors on the collapsibility characteristics such as initial conditions. Three types of gypseous soils had been experimented in this study, sandy gypseous soil from different parts of Iraq. Large-scale model with soil dimensions $(700 * 700 * 600) \mathrm{mm}$ was used to show the effect of water content-changes in different relations (collapse, stress and suction with time relations). The study showed that the collapse-potential, the soil-suction and the soil-strength were affected by the initial-conditions (water-content and dry unit weight). The collapse potential for all soil types increased when the water content increased due to a reduction in matric suction of the soil. The small value of the collapse that was obtained for all models was related to a number of factors such as dense condition, high compaction, capillary tension and cementing agent between soil particles. All these reasons make soil strong and more rigid to collapse.

The study carried out by Ashour et al. (2020) included large numbers of sandy and silty specimens of collapsible soils with different initial conditions to develop a correlation that evaluated the collapse potential $\mathrm{Cp}$ of the soil due to inundation. The presented model 
reflected the significant influence of degree of saturation $\mathrm{Sr}$ on $\mathrm{Cp}$ of inundated soil which considerably decreased by the increase of Sr. The determined properties of inundated collapsed soil, such as void ratio and angle of friction were employed to construct the post-inundation stress-strain curve. Comparisons between predicted and measured stressstrain curves of inundated collapsible soils were presented for validation. A brief review of some of these ANNs related researches is be presented in this paper.

Al-Janabi (2006) utilized multilayer perception training using the back propagation algorithm to build two ANN models, one for dissolved gypsum (DG) and the other for leaching strain (L.S). It was found that ANNs had the ability to predict the dissolved gypsum and leaching strain through process in gypseous soils with a good degree of accuracy.

Sinha and Wang (2008) presented artificial neural network models relating to permeability, maximum dry density and optimum moisture content as output variables with classification properties of the soils. Their study was based on the experimental results for samples of clayey soil. They introduced three ANNs models, one for each maximum dry density, optimum moisture content and coefficient of permeability. In addition to the combined ANNs model to estimate the above output variables together. The prediction models showed good accuracy.

Al-Ani et al. (2009) used artificial neural networks to relate the properties of gypseous soils and evaluated the values of compression of soils under different conditions of soaking and washing. ANNs were used for modeling the settlement ratio for wetting process, $(\mathrm{S} / \mathrm{B}) \mathrm{w}$, and the settlement ratio for soaking process, $(\mathrm{S} / \mathrm{B}) \mathrm{s}$ (where $\mathrm{S}$ is the settlement of footing of width B and w and s refer to washing and soaking, respectively). It was found that ANNs had the ability to predict the compression of gypseous soil due to soaking and washing process with high degree of accuracy. The results also showed that the initial gypsum content, stress level and time had smaller impact on the settlement ratio than other variables. It was concluded that the ANNs had the ability to predict the $(\mathrm{S} / \mathrm{B}) \mathrm{W}$ and (S/B)s of gypseous soil with high degree of accuracy. The equations obtained using ANNs for $(\mathrm{S} / \mathrm{B}) \mathrm{w}$ and $(\mathrm{S} / \mathrm{B}) \mathrm{s}$ showed excellent correlation with experimental results where the coefficients of correlation were (0.9541) and (0.991), respectively.

Tizpa et al. (2015) presented ANNs prediction models that correlated compaction parameters, permeability, and shear strength with the soil index characteristics that could be measured easily. They utilized the datasets of the geotechnical laboratory of the University of Bahia in Brazil. Their obtained results showed high accuracy for ANNs prediction models when compared with the experimental datasets.

The objectives of the study were to investigate leaching-permeability behavior of collapsible gypseous soils and to develop ANN models for estimating the saturated coefficient of permeability and solubility of the soils. 


\section{MATERIALS AND METHODS}

\section{Materials and Testing Procedures}

The leaching-permeability experiments were carried out on disturbed mixed soil specimens taken from Baher Al-Najaf west of Iraq, the gypsum content ranged between 17\% and $36 \%$. Hydraulic experiments of leaching - permeability were conducted to investigate the saturated permeability and solubility of soil specimens. The soil samples were remolded to match the natural soil condition, i.e., the field density state. In this work, the soil specimens were leached in the constant head permeameter, initially carried out by permitting the soil specimen to saturate by maintaining the same water level in the inlet and outlet. Then, the water level in the inlet was raised and preserved at a constant level to output flow at a specific hydraulic gradient. A hydraulic gradient of 6.67, corresponding to a head of $1.0 \mathrm{~m}$ was considered to produce a significant fluctuation in groundwater elevation in the studied area. The testing procedures used by Ismael (1993) and Ismael and Mollah (1998) were modified to suit the present work conditions.

The testing procedures were conducted according to Ismael (1993) and Ismael and Mollah (1998). The samples were $70 \mathrm{~mm}$ in diameter and $150 \mathrm{~mm}$ in height, the main parts of the leaching device used comprised of constant head permeameter, water reservoir, and graduated cylinder to collect the leached water. The soil samples were poured inside the permeameter cylinder in layers with the vibration to reach the desired field density. Water from the reservoir was passed through the specimen at its bottom to drain at the top in order to simulate the soil saturation in the field due to rising of ground water table. Readings for total dissolved salts (TDS), temperature, $\mathrm{pH}$, and electrical conductivity (EC) of the of leachate discharge that was accumulated in cylinder every one hour during the experiment period. The variations in the above parameters were recorded and used to evaluate the degree of salts dissolution of the soil samples. Leaching was assumed to have been terminated when the reading of these measuring units showed no further decrease. The experiments were conducted utilizing the setup shown in Figure 1.

The leaching period extended for seven days per each tested soil sample, the process in the laboratory was accomplished using ordinary drinking water.

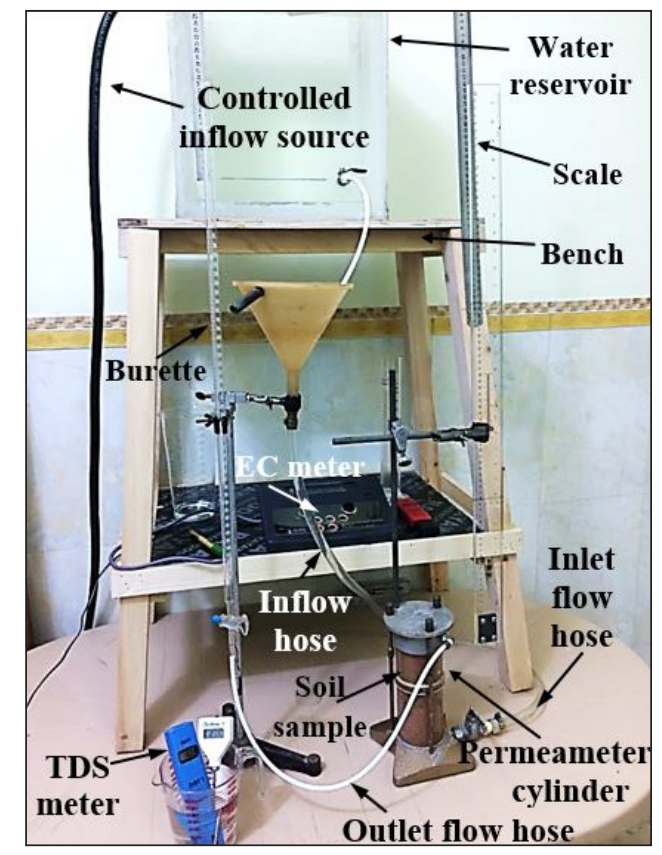

Figure 1. Experiment setup for permeabilityleaching tests 
Three devices were used to measure the dissolved materials, namely: the EC214 an electrical conductivity meter, and two portable devices which were the total dissolvedsolids tester (TDS) and $\mathrm{pH}$ tester as shown in Figure 2. They were manufactured by Hanna Instruments Company, Romania.

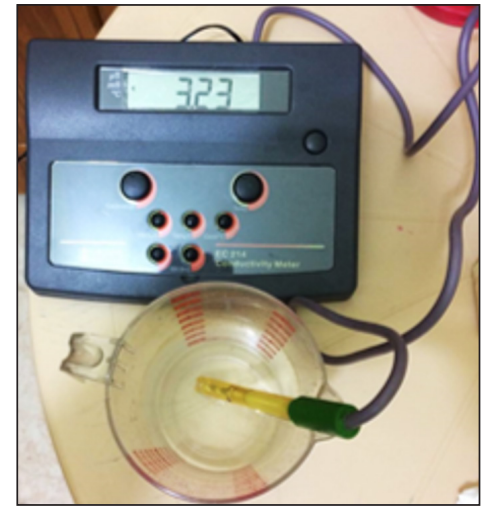

(a)

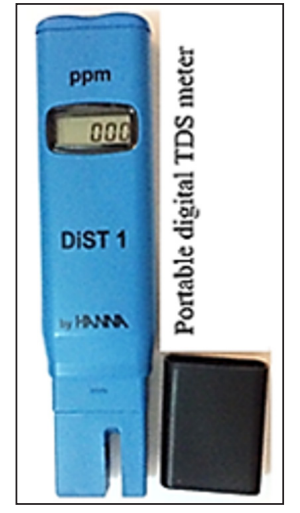

(b)

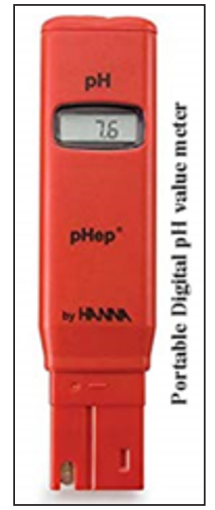

(c)

Figure 2. (a) EC; (b) TDS; and (c) pH value testers

\section{Artificial Neural Network Technique}

The artificial neural networks (ANNs) are preferably suitable for use in the field of water resources and geotechnical engineering since it can make use of heuristic knowledge or pattern matching method instead of resolving the mathematical equations. ANNs considered as computational tools that have the ability to learn with time and adjust the trend of varying of definite parameter in an explicit data (Al-Lamy, 2008). The ANNs structure and operation contain of a number of artificial neurons identified as" nodes" or "units "that is typically organized in layers namely; input layer, output layer and one or more hidden layers as shown in Figure 3.

According to Shahin et al., (2001) and Sinha and Wang (2008), the above architecture is termed multilayer perceptrons (MLPs) that consist of three layers ANNs, which is the furthermost widely used in geotechnical engineering. In this study, the four input variables per each site involved to implement the ANNs model are; total dissolved salts (TDS) expressed in part per millions (ppm), electric conductivity (EC) in $\mathrm{ms}$, time $(t)$ in hrs, and temperature of leachate $(\mathrm{T})$ in ${ }^{\circ} \mathrm{C}$. Consequently, the input

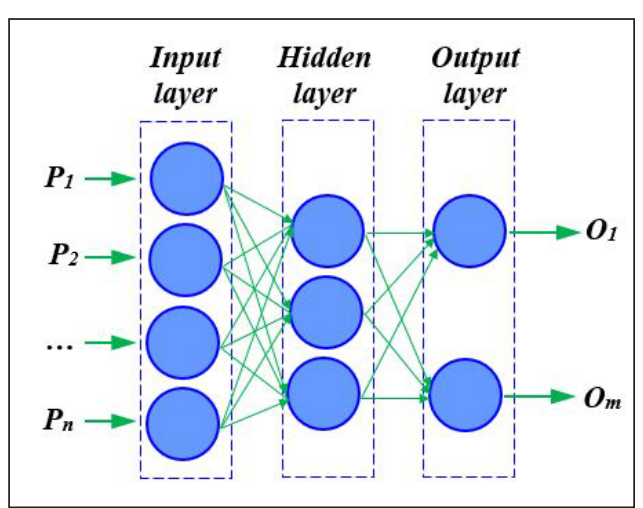

Figure 3. Structure and operation layout of the neural networks 
layer contains four neurons. A typical neural network was established in this study in MATLABR2015a software in which, the saturated coefficient of permeability $\left(\mathrm{K}_{\text {sat. }}\right)$, and the solubility of the gypsum (S) which were expressed as weight percentage and trained with the input variables. The leaching-permeability test results were analyzed together with the percentage of solubility of gypsum to be used as dataset as listed in Table 1 to develop the artificial neural network models.

Table 1

Descriptive statistics of gypseous soil parameters used in the permeability and solubility models

\begin{tabular}{|c|c|c|c|c|c|c|}
\hline $\begin{array}{l}\text { Site } \\
\text { No. }\end{array}$ & $\begin{array}{ll}\text { Statistics } & \text { Parameter } \\
\end{array}$ & $\begin{array}{c}K_{\text {sat. }} \\
(\mathrm{cm} / \mathrm{s.})\end{array}$ & $\begin{array}{c}\text { S\% } \\
\text { by wt. }\end{array}$ & $\begin{array}{c}\text { TDS } \\
(\mathrm{ppm})\end{array}$ & $\begin{array}{c}\text { EC } \\
(\mathrm{ms})\end{array}$ & $\begin{array}{c}\mathrm{T} \\
\left({ }^{\mathrm{O}} \mathrm{C}\right)\end{array}$ \\
\hline \multirow{4}{*}{$\# 1$} & Max. & $1.502 \times 10^{-2}$ & 24.421 & 1577.0 & 3.440 & 24.40 \\
\hline & Min. & $2.148 \times 10^{-3}$ & 0.517 & 1261.0 & 2.450 & 22.30 \\
\hline & Mean & $8.61 \times 10^{-3}$ & 14.973 & 1425.643 & 2.831 & 23.001 \\
\hline & Standard deviation & $2.818 \times 10^{-3}$ & 5.955 & 65.057 & 0.20 & 0.464 \\
\hline \multirow{4}{*}{$\# 2$} & Max. & $2.59 \times 10^{-2}$ & 8.754 & 1529.0 & 3.360 & 23.0 \\
\hline & Min. & $2.01 \times 10^{-3}$ & 1.772 & 1419.0 & 2.90 & 21.500 \\
\hline & Mean & $2.07 \times 10^{-3}$ & 7.008 & 1447.526 & 3.092 & 22.071 \\
\hline & Standard deviation & $4.37 \times 10^{-3}$ & 1.287 & 23.061 & 0.124 & 0.374 \\
\hline \multirow{4}{*}{$\# 3$} & Max. & $2.91 \times 10^{-3}$ & 7.280 & 1503.0 & 3.306 & 21.60 \\
\hline & Min. & $2.10 \times 10^{-3}$ & 4.072 & 1461.0 & 2.94 & 20.41 \\
\hline & Mean & $2.69 \times 10^{-3}$ & 6.546 & 1472.942 & 3.193 & 21.126 \\
\hline & Standard deviation & $2.24 \times 10^{-4}$ & 0.784 & 9.294 & 0.081 & 0.346 \\
\hline
\end{tabular}

\section{RESULTS AND DISCUSSION}

The results of physical and chemical properties of the natural soil samples are presented in Table 2.

During leaching, the leached soil sample is subjected to progressive dissolution of soluble salts within the soil matrix, the leaching effect becomes clearer in soils of high gypsum content. This is due to the fractional abstraction of soluble materials, and the inter-particle binding related to it. The losses in the original weight of the soil sample after starting of the leaching process can be idealized mathematically as Equation 1:

$W_{n}=W_{\circ}-W_{\ell}$

where, $W_{n}=$ the new weight of soil sample after the leaching process at time step $\Delta t,(\mathrm{~N})$, $W_{\mathrm{o}}=$ the original weight of soil sample before the leaching process, (N) and $W_{l}=$ the weight lost from soil sample after the period of $\Delta t$ from starting of the leaching process, $(\mathrm{N})$. 


\begin{tabular}{|c|c|c|c|c|c|c|c|c|c|c|c|}
\hline $\begin{array}{l}\dot{0} \\
\dot{0} \\
\dot{0}\end{array}$ & 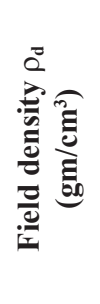 & 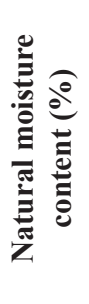 & 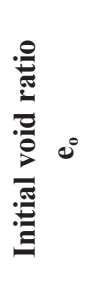 & 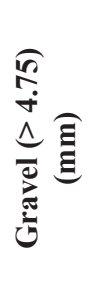 & 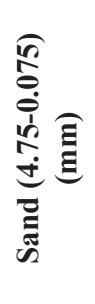 & 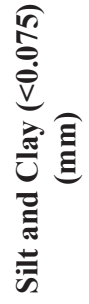 & คิ & 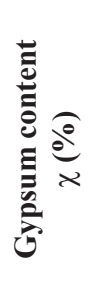 & 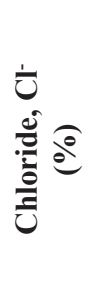 & 竞 & 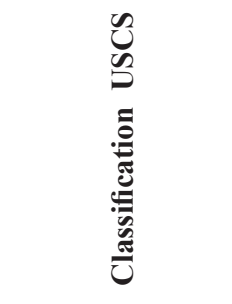 \\
\hline 1 & 1.417 & 1.25 & 0.79 & 20.50 & 78.90 & 0.58 & 1.80 & 40.11 & 0.117 & 8.0 & $\begin{array}{l}\text { SP, Poorly graded } \\
\text { sand with gravel }\end{array}$ \\
\hline 2 & 1.507 & 1.13 & 0.63 & 4.35 & 88.20 & 7.45 & 0.43 & 20.42 & 0.107 & 8.22 & $\begin{array}{c}\text { SP- SM, Poorly } \\
\text { graded clean sand } \\
\text { with silt }\end{array}$ \\
\hline 3 & 1.404 & 0.83 & 0.78 & 12.45 & 84.60 & 2.95 & 2.60 & 28.98 & 0.097 & 8.15 & $\begin{array}{l}\text { SP, Poorly graded } \\
\text { sand }\end{array}$ \\
\hline
\end{tabular}

${ }^{*}$ Averaged values for soil samples per each site

Based on the principle of conservation of mass and due to the dissolution of gypsum and other soluble salts in the soil matrix, the dissolved salts will be diffused in the solution (Equation 2).

$$
W_{l}=\gamma Q \Delta t
$$

where, $\gamma=$ the unit weight of leachate in $\left(\mathrm{F} / \mathrm{L}^{3}\right)$,

$Q=$ the flow rate of water through soil sample in $\left(\mathrm{L}^{3} / \mathrm{T}\right)$, and

$\Delta t=$ time step in $(\mathrm{T})$.

Simplifying Equation 2 yields Equation 3 and Equation 4:

$W_{l}=\gamma x K_{\text {sat. }}$ i $A x \Delta t$

where, $K_{\text {sat. }}=$ saturated coefficient of permeability for the soil in $(\mathrm{L} / \mathrm{T})$,

$i=$ the hydraulic gradient (dimensionless), and

$A=$ the cross sectional area of the soil sample in $\left(\mathrm{L}^{2}\right)$.

$W_{\ell}=\left(T D S_{L}-T D S_{w}\right) \times K_{\text {sat. }} i A \times \Delta t$

where, $T D S_{L}=$ the total dissolved salts in the leachate in $\mathrm{F} / \mathrm{L}^{3}$, and

$T D S_{w}=$ the total dissolved salts in the water in $\mathrm{F} / \mathrm{L}^{3}$. The range for $T D S_{w}$ considered in this work is 590 to $630 \mathrm{ppm}$ for a range of temperatures $\left(22\right.$ to $\left.24.5^{\circ} \mathrm{C}\right)$. 
Rearranging both sides of Equation 4 for the next time step, gives Equation 5:

$$
W_{l t_{j+1}}=W_{l t_{j}}-K_{s a t .} i A \times\left(T D S_{L}^{t_{j+1}}-T D S_{w}\right)\left(t_{j+1}-t_{j}\right)
$$

where, $\mathrm{W}_{\mathrm{Itj}}=$ the weight of soil sample leachate from the previous time step.

Substitution Equation 4 in Equation 1, then the net weight of leachate soil at the end of leaching process can be expressed as Equation 6:

$$
W_{n}=W_{\circ}-i A \times \sum_{j=0}^{j=n}\left(T D S_{L}^{j}-T D S_{w}\right)\left(t_{j+1}-t_{j}\right) \times K_{s a t}
$$

The percentage of the soluble weight at any time of leaching periodpointed out as solubility percentage (Equation 7):

$$
\% S_{\text {by wt. }}^{t_{j+1}}=\frac{W_{\ell}^{t_{j+1}}}{W_{o}} \times 100
$$

where, $\% S_{b y w t .}^{t_{j+1}}$ is the percentage of the soluble weight, and

$t_{j+l}$ is the time step within leaching period at which removal weight is calculated.

It is noticed that Equation 5 may use an average value of $\mathrm{K}_{\text {sat. }}$ that is obtained at the end of the leaching period. For more precise results, the value of $\mathrm{K}_{\text {sat. }}$ could be measured and used at the end of each time step from the starting of the leaching process as adopted in Equation 6. Figure 4 presents the removal or soluble weight (averaged at one day intervals up to seven days testing period of leaching process) due to the dissolution of minerals

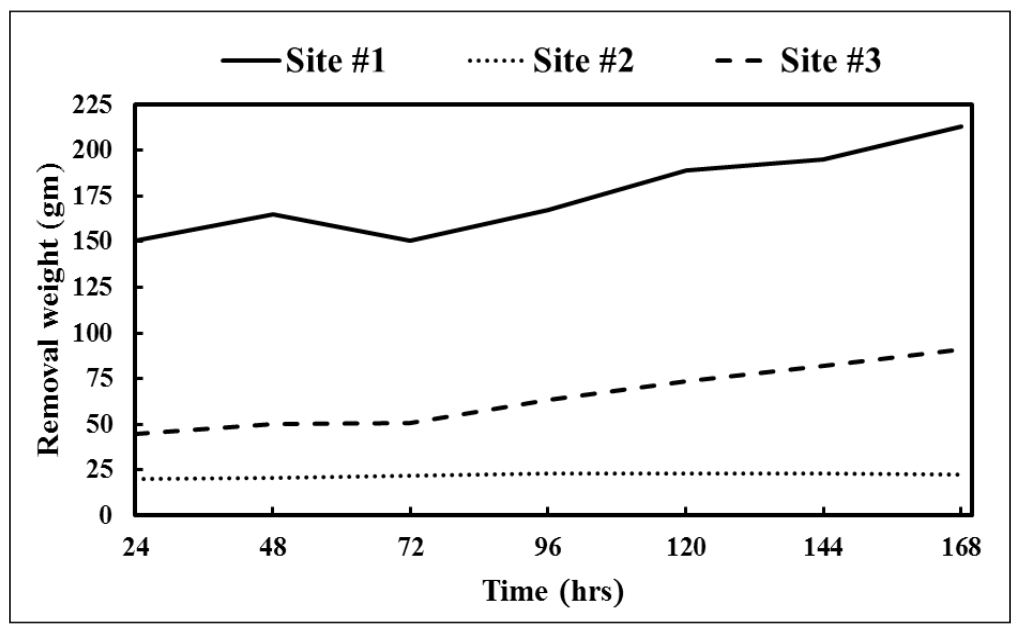

Figure 4. Removal weight for gypseous soil from different sites with leaching time 
from leached soil sample versus time of leaching for the three sites. The original weights of soil samples before the leaching process per each site were $6.29 \mathrm{~N}, 6.69 \mathrm{~N}$, and $6.24 \mathrm{~N}$, respectively. Figure 4 shows the variation of removal weights from gypseous soil samples taken from different sites.

Results from Figure 4 show increasing the dissolution with time for soils at both sites $\# 1$ and \#3 before roughly reaching a steady value. While for site \#2, the dissolution was not increased significantly with time and the trend was maintained constant. The initial content of gypsum and the presence of perceptible content of chloride salts play a significant role as they change during the leaching process. In addition, the mutual interaction of soluble salts leads to a higher increase of the solubility rates that implies the expansion of voids and increasing the soil's permeability, while for field condition, the permeability probably

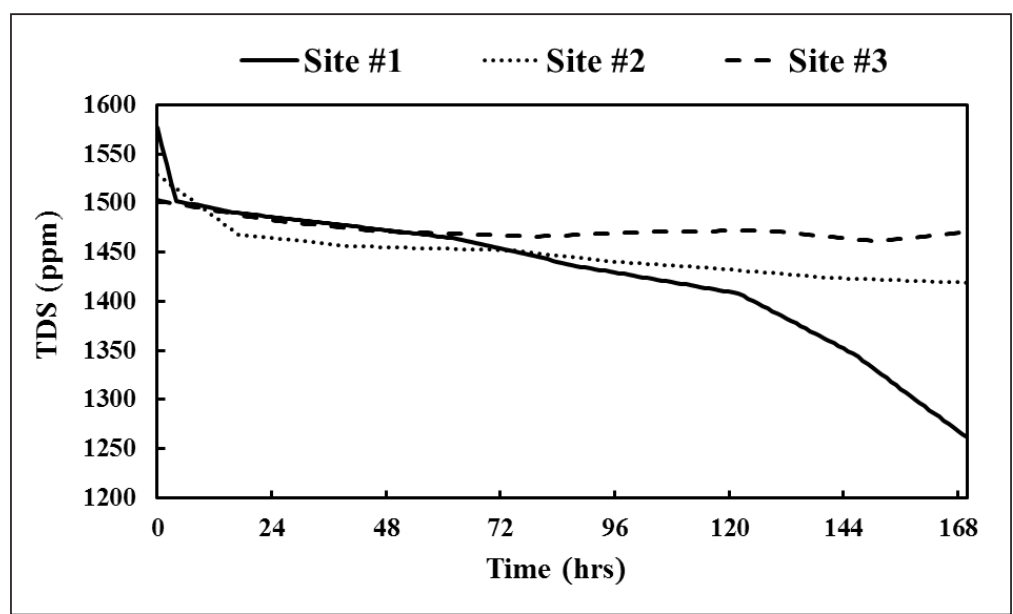

Figure 5. Variation of TDS of gypseous soils from different sites with leaching time

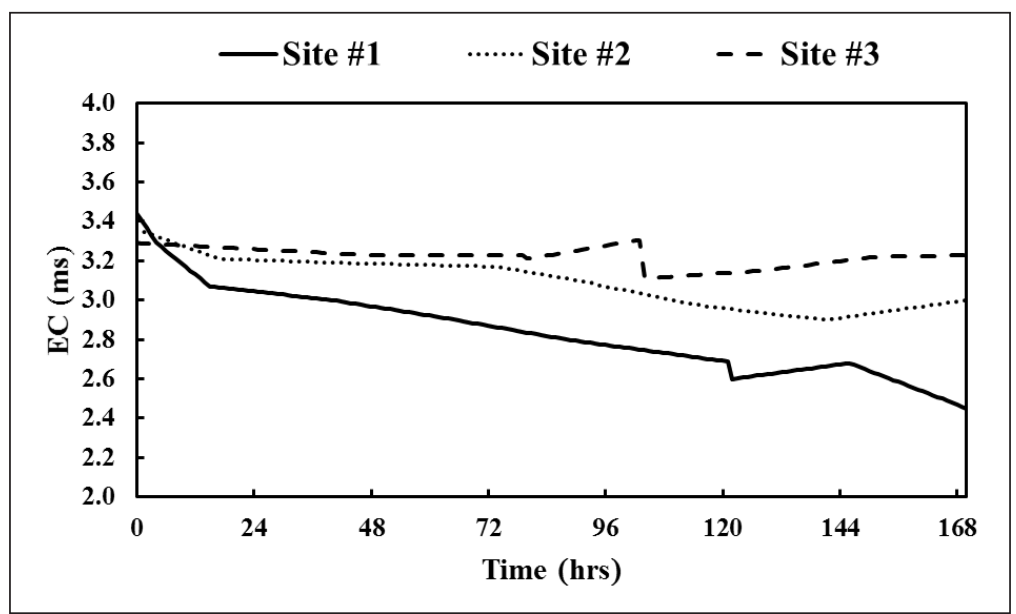

Figure 6. Variation of EC of gypseous soils from different sites versus leaching time 
decreases as a consequence to the collapse of soil structure under the impact of applied loads (Fattah et al., 2019). Figure 5 to 8 show the variations of studied parameters [i.e., TDS in ppm, EC in ms, the percent the percent of solubility S\% by weight, and saturated coefficient of permeability $\left(\mathrm{K}_{\text {sat. }}\right)$ in $\mathrm{cm} / \mathrm{s}$.] with leaching time.

The TDS and EC versus time curves at different sites are shown in Figure 5 and 6 , respectively. It is evident that TDS and EC measures decreased rapidly to around $(20 \%$ and $29 \%$ ) for site \# 1 throughout the seven days of leaching process, whereas the measured TDS and EC values decreased slightly to about $7 \%$ and $11 \%$ for site $\# 2$ and the rates were about $2.2 \%$ and $1.9 \%$ for site \#3. It is expected that the infiltrated water into the soil specimen for each site dissolved the concentrated soluble salts causing the release of ions and elements, which affected the electric conductivity of the leachate, but this did not reflect the similar declining trend for all sites. Eventually, the rapid trends of decrease were more widely clear for site \#1 than those of the other sites as it is obvious from Figure 5 and 6, respectively. The initial gypsum content was lumped and compacted on grains of sand and gravel. Later, the leaching process caused structural weakness and loss of the bonds provided by gypsum. The voids were enlarged and occupied by the increased water as stated by Nashat (1990).

Figure 7 shows the variations of the coefficient of permeability under saturated condition versus leaching time. The initial value of steady-state coefficients of permeability was around a value of $1.5 \times 10^{-3} \mathrm{~cm} / \mathrm{s}$ per each site, the rates of increase in $\mathrm{K}_{\text {sat. }}$ were $1.4 \%$, $2.4 \%$ and $0.07 \%$ for these sites, respectively. The higher rate for site \#2 was probably attributed to the progressive erosion of fines due to piping. In addition to the dissolution of salts contributed to a weight loss of this sample. Despite that the Site \#2 samples had a rather lower gypsum content (Table 2).

Results in Figure 8 reveal the percentage of solubility for three different sites versus time. It is evident that the Site $\# 1$ sample yielded higher $\% \mathrm{~S}$ of $24.2 \%$ in comparison with $7.0 \%$ and $3.1 \%$ for Sites \#2 and \#3, respectively. Subsequently the soil samples taken from site \#1, which had the higher content of soluble minerals as given in Table 2, then lost more gypsum/salt by weight. The $\mathrm{pH}$ measurements of the leachate from the soil samples taken from three sites investigated in this work were roughly constant as given in Table 2. These results are indicating the slight sensitivity of the $\mathrm{pH}$ values of the various contents of soluble salts. The $\mathrm{pH}$ measurements of the leachate from the soil samples taken from three sites investigated in this work were roughly constant as given in Table 2. These results indicate the slight sensitivity of the $\mathrm{pH}$ values for various contents of soluble salts.

As noticed from the forgoing results and discussion, in addition to results given in Table 3 , the traditional nonlinear correlation equations for permeability and solubility per each site are proposed. The results showed that prediction model of the saturated coefficient of permeability did not provide strong relation. Hence, there is a difficulty to develop a general precise model for permeability and/or solubility via the traditional statistical techniques 


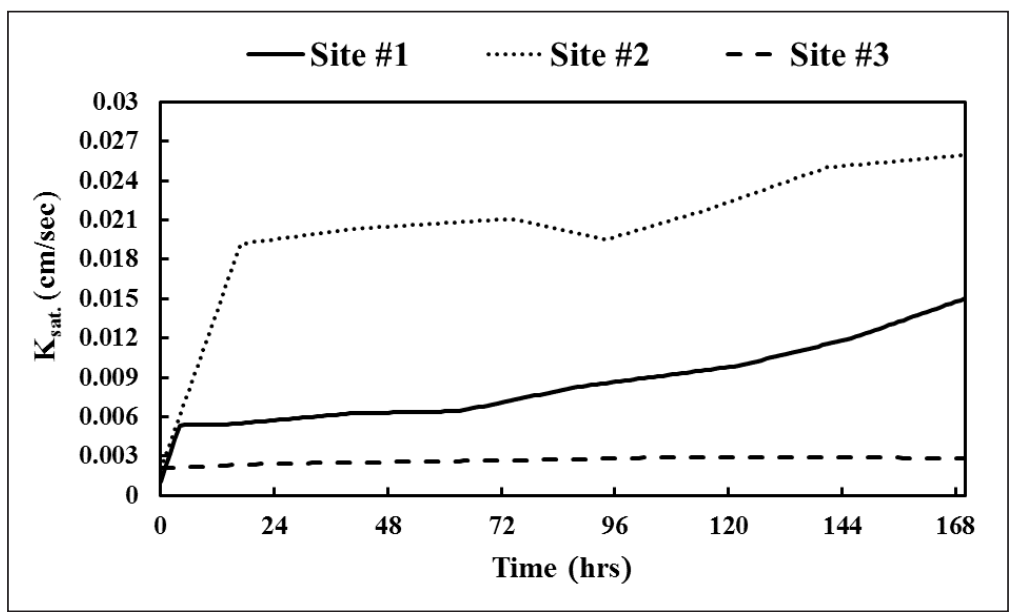

Figure 7. Variation of $\mathrm{K}_{\text {sat. }}$ of gypseous soils from different sites with leaching time

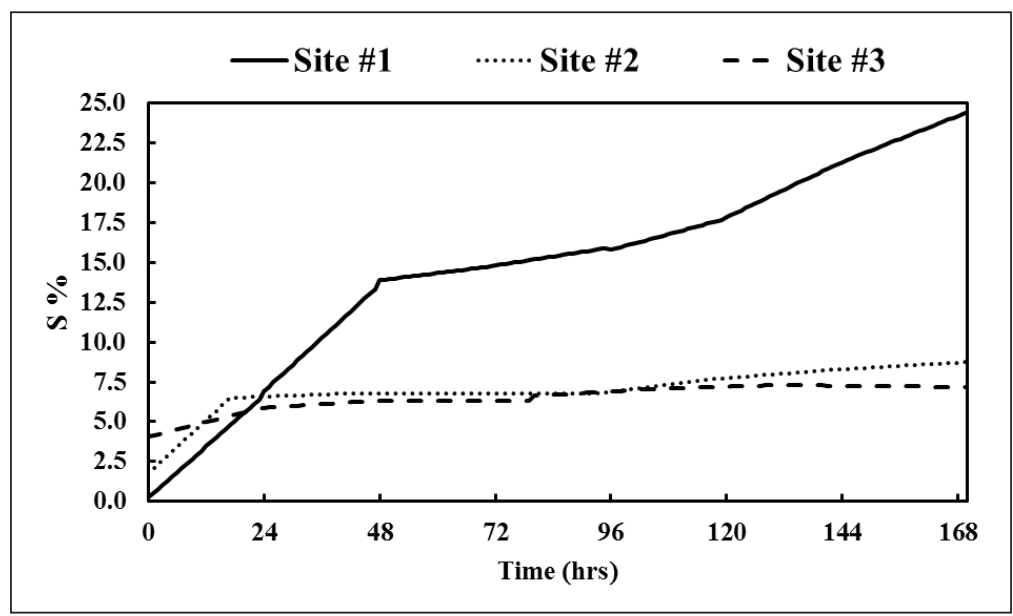

Figure 8 . Variation of $\% \mathrm{~S}$ of gypseous soils from different sites with leaching time

in order to correlate overall affecting variables to include the studied sites although that the data include sufficient geotechnical and chemical properties in addition to the gypsum contents.

Comparisons between Figure 4 to 8 reveals that the decrease in TDS and EC with time was related to the increase of removal of soil weight, saturated permeability, and solubility percent.

Collapse may not induce the real problem of collapsible soil because full saturation of soil samples is not maintained. Fattah et al. (2017) concluded that the collapse potential resulted from complete wetting of soil layer might not be achieved in the field, due to the inability to reach full saturation state through a single step wetting. Therefore, the multistep wetting procedure is more convenient due to the slowly rising of ground water by 
Table 3

Traditional correlation models

\begin{tabular}{|c|c|c|c|}
\hline $\begin{array}{l}\text { Site } \\
\text { No. }\end{array}$ & $\begin{array}{c}\text { Dependent } \\
\text { Variable }\end{array}$ & Correlation Model & $\begin{array}{c}\text { Coefficient of } \\
\text { Determination } \\
\left(\mathbf{R}^{2}\right)\end{array}$ \\
\hline \multirow{4}{*}{$\# 1$} & \multirow{2}{*}{$K_{\text {sat. }}(\mathrm{cm} / \mathrm{s})}$. & $K_{\text {sat }}(T D S)=-4.0 \times 10^{-4} T D S+0.0707$ & 0.9876 \\
\hline & & $K_{\text {sat }} .(E C)=0.0127 E C^{2} 0.0861 E C+0.1501$ & 0.9418 \\
\hline & \multirow{2}{*}{$\% S$} & $\% S(T D S)=-0.0004 T D S^{2}+0.9501 T D S-587.98$ & 0.8986 \\
\hline & & $\% S(E C)=-28.429 E C+95.334$ & 0.929 \\
\hline \multirow{4}{*}{$\# 2$} & \multirow{2}{*}{$K_{\text {sat. }}(\mathrm{cm} / \mathrm{s})}$. & $K_{\text {sat. }} .(T D S)=-1.0 \times 10^{-6} T D S^{2}+0.0026 T D S-1.7556$ & 0.9374 \\
\hline & & $K_{\text {sat }} .(E C)=-0.1393 E C^{2}+0.8334 E C-1.2226$ & 0.8074 \\
\hline & \multirow{2}{*}{$\% S$} & $\% S(T D S)=-0.0545 T D S+85.835$ & 0.9524 \\
\hline & & $\% S(E C)=-36.511 E C^{2}+216.93 E C-314.12$ & 0.8719 \\
\hline \multirow{4}{*}{$\# 3$} & \multirow{2}{*}{$K_{\text {sat. }}(\mathrm{cm} / \mathrm{s})}$. & $K_{\text {sat }} .(T D S)=487.28 e^{-0.008 T D S}$ & 0.7721 \\
\hline & & $K_{\text {sat }} .(E C)=-0.4831 E C^{2}+3.1041 E C-4.9833$ & 0.9605 \\
\hline & \multirow{2}{*}{$\% S$} & $\% S(T D S)=1 \times 10^{09} e^{-0.013 T D S}$ & 0.8171 \\
\hline & & $\% S(E C)=1438.1 E C^{3}-13933 E C^{2}+44975 E C-48364$ & 0.5277 \\
\hline
\end{tabular}

capillary forces, especially in the low rainfall regions. So that, the results of leaching are more appropriate to present the problem of collapsible soil.

\section{Estimation of the Separated ANN Models for $K_{\text {sat. }}$ and $S \%$ by Weight}

Determination of the ANNs architecture is considered as a major and difficult objective in ANN's model derivation (Shahin, 2003). Four variables were involved as input, the throughout dataset consisting of 513 samples which were divided into two subsets as training set and test set, thus randomly about $11 \%$ of the throughout data (56 inputs) were extracted as test set, the remaining 457 inputs or $89 \%$ of the over data were used as training set. The neural network properties used in this study were as follows. The training network type was a feed-forward back propagation technique. The multilayer perceptron network was adopted including three layers, four to ten neurons were experienced in order to reach to the best number of neurons in hidden layer per each model, the models consisted of eight neurons. The training function is "TRAINGDX" which updates weights and bias values by gradient descent rule to back- propagation errors through the network, the transfer (activation) function is "LOGSIG" which calculates a layer's output from its net input. A detailed demonstration of this function is available in the literature such as Shahin (2003). The performance of training was maintained by the mean squared error (MSE) criterion for an epochs number of 1000 . The architecture of an ANN for estimating both $\mathrm{K}_{\text {sat. }}$ and $\mathrm{S} \%$ by weight is shown in Figure 9. 


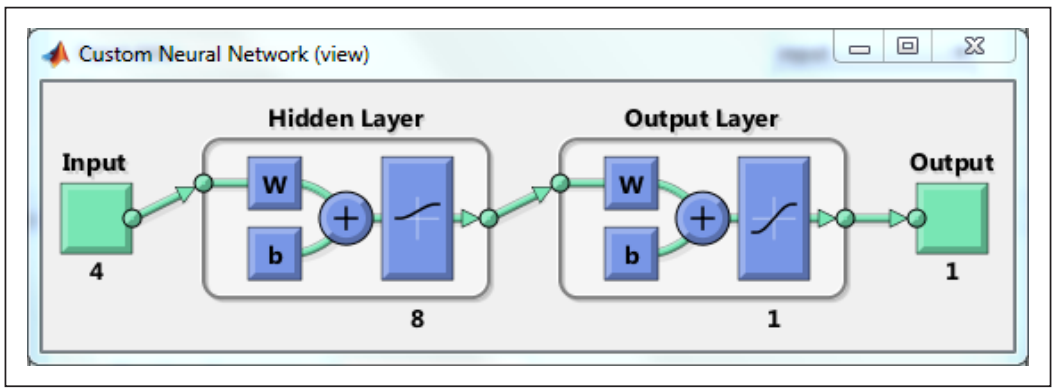

Figure 9. Architecture of ANN model predictions for $\mathrm{K}_{\text {sat. }}$ and $\mathrm{S} \%$ by weight

\section{Statistical Evaluation of the ANN Models}

In this study, some statistical approaches were used to evaluate the ANN models, these statistics are coefficient of correlation (R), root mean square error (RMSE), and coefficient of residual mass (RM).

The coefficient of correlation $(\mathrm{R})$ can be calculated as Equation 8:

$$
R=\frac{\sum_{i=1}^{n}\left(x_{i}-\bar{X}\right)\left(y_{i}-\bar{Y}\right)}{\sqrt{\sum_{i=1}^{n}\left(x_{i}-\bar{X}\right)^{2} \sum_{i=1}^{n}\left(y_{i}-\bar{Y}\right)^{2}}}
$$

where, $x_{i}$ is the desired (measured) output, $x_{i}=x_{1}, x_{2}, \ldots, x_{n}, y_{i}$ is the model (predicted) output, $\mathrm{y}_{\mathrm{i}}=\mathrm{y}_{1}, \mathrm{y}_{2}, \ldots ., \mathrm{y}_{\mathrm{n}}, \overline{\mathrm{X}}$ and $\overline{\mathrm{Y}}$ are the mean measured and predicted output, respectively, and $\mathrm{n}$ is the number of data.

The root mean square error (RMSE) can be calculated as Equation 9:

$$
R M S E=\sqrt{\frac{\sum_{i=1}^{n}\left(y_{i}-x_{i}\right)^{2}}{n}}
$$

The coefficient of residual mass (RM) can be determined as Equation 10 (Tizpa et al., 2015):

$$
R M=1-\frac{\sum_{i=1}^{n} y_{i}}{\sum_{i=1}^{n} x_{i}}
$$

The coefficient of correlation is a measure that is used to determine the relative correlation and the goodness of fit between the predicated and measured data; while, the RMSE is the most popular measure of error and has the advantage that large error receives much greater attention than small errors (Al-Lamy, 2008). Tizpa et al. (2015) stated that the RMSE expressed the residual error variance; if the output fitted a dataset, 
its value was minimum. When the value of RMSE is lower, the accuracy of the predicted model accordingly is higher, for the value RMSE is equal zero, a perfect fit is the case. The coefficient of residual mass, RM, is a different analysis of the measured and predicted outputs. The ideal value of RM is zero, whereas negative values indicate overestimation and vice versa. For evaluating the overall validity of ANN prediction models, assessments were performed by the ANN training regression plots as shown in Figure 10 that shows the comparing values for the coefficient of correlation between training and testing of the

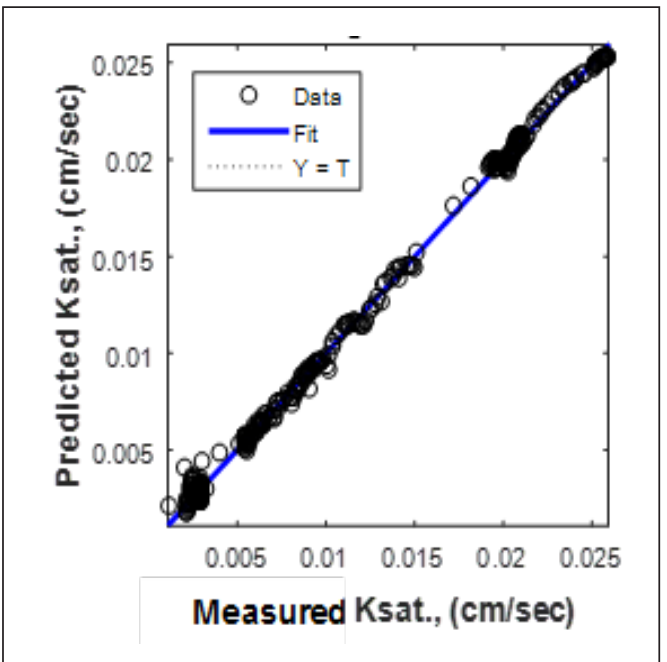

(a)

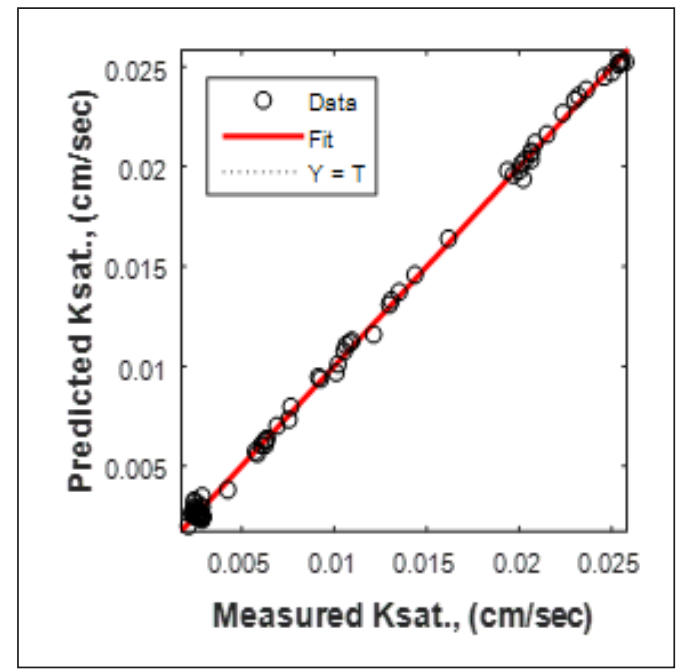

(b)

Figure 10. Neural network training regression of ANN model for the coefficient of permeability: (a) Training for $\mathrm{K}_{\text {sat. }}$ model; and (b) Test of $\mathrm{K}_{\text {sat. }}$ model

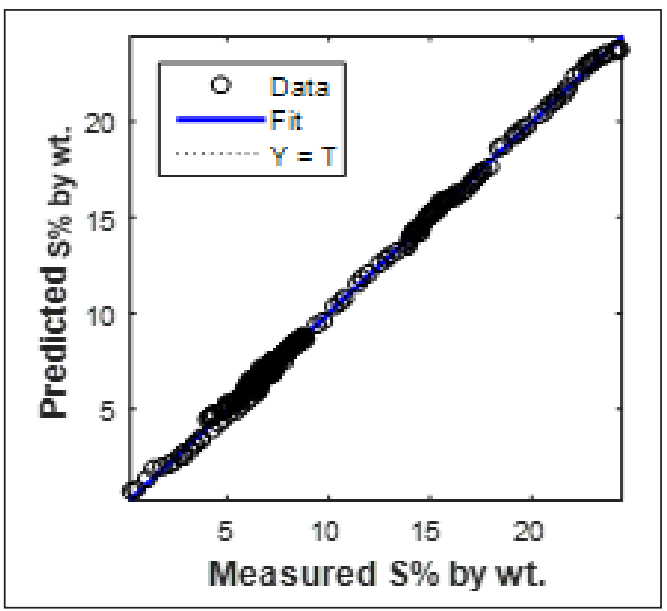

(a)

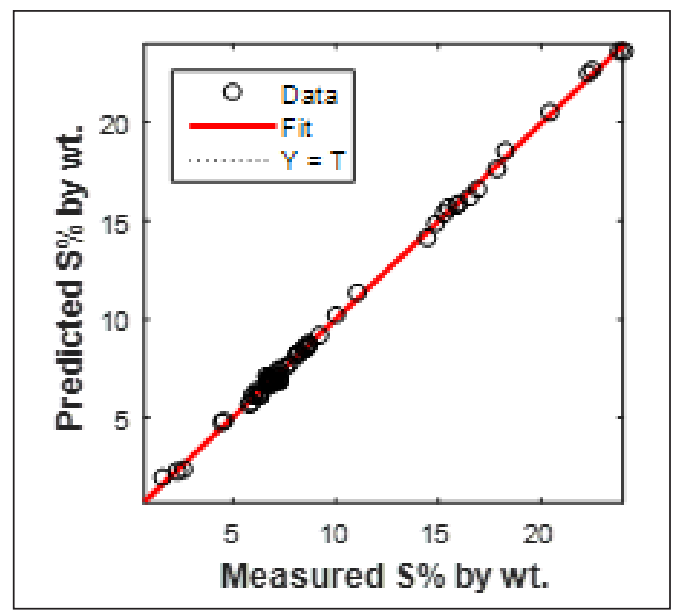

(b)

Figure 11. Neural network training regression of ANN model for the solubility percentage by weight: (a) Training for $\mathrm{K}_{\text {sat. }}$ model; and (b) Test of $\mathrm{K}_{\text {sat. }}$ model 
Table 4

Models evaluation criterion

\begin{tabular}{ccccc}
\hline & Statistics & R\% & RMSE & RM \\
\hline & & & & \\
& & 99.9912 & $3.41 \times 10^{-04}$ & $7.16 \times 10^{-04}$ \\
& $\mathrm{~K}_{\text {sat. }}(\mathrm{cm} / \mathrm{s})$. & 99.93 & 0.1957 & $1.52 \times 10^{-04}$ \\
\hline
\end{tabular}

model. It is evident that acceptable correlation is obtained, and Figure 10 indicates a good correlation since $\mathrm{R}$ approaches to unity. Also, a perfect agreement was obtained between the measured and predicted values as indicated by the overall correlation coefficient.

Figure 11 shows the training regression plots for ANN model of the percent of solubility $\mathrm{S} \%$ by weight. Results of Figure 11 reveal that as for $\mathrm{K}_{\text {sat. }}$ model, a higher correlation is obtained between the training and testing of the $\mathrm{S} \%$ model. As well as, a complete covenant between the measured and predicted values occurs as shown by the overall correlation coefficient.

Table 4 summarizes the statistical evaluation criterion for both ANN models. It can be noticed that acceptable values for the statistic parameters are obtained. It is concluded that strong correlations for prediction of both $\mathrm{K}_{\text {sat. }}$ and $\mathrm{S} \%$ could be obtained.

\section{CONCLUSIONS}

Based on the results of this study, the following conclusions may be drawn:

- The gypseous soils exhibited a high rate of dissolution of soluble minerals content, which caused increase in the coefficient of permeability as the soil samples reached the state of long-term full saturation.

- Artificial neural networks had the capabilities to predict the saturated coefficient of permeability $\left(\mathrm{K}_{\text {sat. }}\right)$ and solubility percentage by weight $(\mathrm{S})$ as a function to TDS, $\mathrm{EC}, \mathrm{T}$, and $t$ of gypseous soil with higher accuracy according to the statistical parameters as the coefficient of correlation ranged between $99.99 \%$ and $99.93 \%$.

- The leaching-permeability behavior of collapsible gypseous soils had been dealt with to develop ANN models for estimating the saturated coefficient of permeability and solubility of the soils. The datasets used in the model development had involved significantly the most influencing factors that might affect both the permeability of gypseous soils and solubility percentage which were TDS, EC, the temperature of leachate $(\mathrm{T})$, and leaching time $(t)$ of gypseous soil. These factors are usually faced in the practice of engineering.

\section{ACKNOWLEDGEMENT}

The authors would like to acknowledge the Civil Engineering Department of the University of Technology - Iraq for support and encouragement. 


\section{REFERENCES}

Al-Ani, M. M., Fattah, M. Y., \& Al-Lamy, M. T. A. (2009). Artificial neural networks analysis of treatment process of gypseous soils. Engineering and Technology Journal, 27(9), 1811-1832.

Al-Janabi, K. R. M. (2006). Laboratory leaching modelling in gypseous soils using artificial neural network $(A N N)$ (PhD Thesis). University of Technology, Baghdad, Iraq.

Al-Lamy, M. T. A. (2008). The use of acrylate in grouting some Iraqi gypseous soils (PhD Thesis). University of Technology, Baghdad, Iraq.

Ashour, M., Abbas, A., Altahrany, A., \& Alaaeldin, A., (2020). Modelling the behavior of inundated collapsible soils. Engineering Reports, 2(2), 1-14. doi: https://oi.org/10.1002/eng2.12156.

Barzanji, A. (1973). Gypsiferous soils in Iraq (PhD thesis). University of Ghent, Belgium.

Fattah, M. Y., \& Dawood, B. A. (2020). Time-dependent collapse potential of unsaturated collapsible gypseous soils. World Journal of Engineering, 17(2), 283-294. doi: 10.1108/WJE-09-2019-0276.

Fattah, M. Y., Hameedi, M. K., \& Aswad, M. F. (2017). Determination of collapse potential of gypseous soil from field and laboratory tests. Diyala Journal of Engineering Sciences, 10(2), 75-85.

Fattah, M. Y., Obead, I. H., \& Omran, H. A. (2019). A study on leaching of collapsible gypseous soils. International Journal of Geotechnical Engineering, 2019, 1-11. doi: 10.1080/19386362.2019.1647664

Ibrahim, A. N., \& Schanz, T. (2017), Improvement of gypseous soil strength by silicone oil. Soil Mechanics and Foundation Engineering, 54(2), 117-121. doi: https://doi.org/10.1007/s11204-017-9443-7

Ismael, N. F. (1993). Laboratory and field leaching tests on coastal salt-bearing soils. Journal of Geotechnical Engineering, 119(3), 53-470. doi: https://doi.org/10.1061/(ASCE)0733-9410(1993)119:3(453)

Ismael, N. F., \& Mollah, M. A. (1998). Leaching effects on properties of cemented and sands in Kuwait. Journal of Geotechnical and Geoenvironmental Engineering, 124(10), 997-1004. doi: https://doi.org/10.1061/ (ASCE)1090-0241(1998)124:10(997)

Nashat, I. H. (1990). Engineering characteristics of some gypseous soils in Iraq (PhD Thesis). University of Baghdad, Baghdad.

Shahin, M. A. (2003). Use of artificial neural networks for predicting settlement of shallow foundations on cohesionless soils ( $\mathrm{PhD}$ Thesis). University of Adelaide.

Shahin, M. A., Jaska, M. B., \& Maier, H. R. (2001). Artificial neural networks application in geotechnical engineering. Australian Geomechanics, 36(1), 49-62.

Sinha, S. K., \& Wang, M. C. (2008). Artificial neural network prediction models for soil compaction and permeability. Geotechnical and Geological Engineering, 26(1), 47-64. doi: https://doi.org/10.1007/ s10706-007-9146-3

Tizpa, P., Chenari, R. J., Fard, M. K., \& Machado, S. L. (2015). ANN prediction of some geotechnical properties of soil from their index parameters. Arabian Journal of Geosciences, 8, 2911-2920. doi: https://doi. org/10.1007/s12517-014-1304-3.doi:10.1007/s12517-014-1304-3 